\title{
Mechanism Analysis of PCC Harmonic Resonance Based on Nonlinear Self-Oscillation Concept in a High-Power Grid-Tied Photovoltaic Plant
}

\author{
Yong Zhao, Zilong Yang *, Yibo Wang and Ying Zhang \\ Key Laboratory of Solar Thermal Energy and Photovoltaic Systems, Institute of Electrical Engineering Chinese \\ Academy of Sciences, Beijing 100190, China; zhaoyong@mail.iee.ac.cn (Y.Z.); wyb@mail.iee.ac.cn (Y.W.); \\ zhangying2011@mail.iee.ac.cn (Y.Z.) \\ * Correspondence: yangzl@mail.iee.ac.cn; Tel.: +86-10-8254-7024
}

Received: 29 July 2018; Accepted: 29 August 2018; Published: 1 September 2018

Featured Application: The results of this study can be applied to the harmonic analysis of micro-grids, especially weak grids with renewable energy generation systems.

\begin{abstract}
With the high penetration of photovoltaic systems, the interaction between grid-tied inverters and line impedances results in harmonic resonance at point of common coupling (PCC) in high-power photovoltaic (PV) plants. Thus far, most publications have reported about this issue from a theoretical perspective, and there is no field verification in a real PV plant. To fill this gap, field waveforms are captured in a high-power PV plant to figure out the mechanism of the harmonic resonance phenomenon. This paper, for the first time, presents a nonlinear self-oscillation concept to clarify the mechanism of the harmonic resonance in a high-power PV plant. The field harmonic measurement of a grid-tied PV plant is carried out. The analysis of harmonic spectra and current distributions in a photovoltaic plant shows that these harmonic characteristics are different from the signals generated by the resonances of PV inverter output filters. The correlation of frequency, phase sequence and amplitude show that the different harmonics at PCC are generated by the same source inside PV inverters. Based on the comparison of PCC harmonics with periodic steady-state outputs of nonlinear systems, the nonlinear self-oscillation concept is proposed to clarify the mechanism of the harmonic resonance in a high-power PV plant. The tests in field and signal analysis verify the effectiveness of the proposed method and solution.
\end{abstract}

Keywords: grid-tied PV plant; harmonic resonances; nonlinear self-oscillation concept

\section{Introduction}

Due to fossil fuel depletion and environmental pollution around the world, the development of renewable energy, such as wind and photovoltaic, has attracted much attention [1-4]. The distributed generation (DG) systems based on renewable energy can be connected in parallel with each other to form a micro-grid. The analysis of field data of photovoltaic (PV) plants indicates that the harmonics at point of common coupling (PCC) in weak grid can exist stably for a long time and the line impedances of low-voltage power distribution systems cannot be ignored [5]. Harmonics in micro-grid may cause abnormality of distribution system and even damage of power facilities, further reducing power quality and even causing the shutdown of PV inverters [6]. In [7,8], the PV inverters operated in parallel can shift the resonant frequency to a low frequency band, and these resonances of inverters can take place at the frequencies of 5 th and 7th harmonics. With the high penetration of nonlinear power electronics devices, the impact harmonic resonance between inverters and grid is more complicated. Traditionally, many studies are only implemented for a single power electronic equipment and single renewable energy 
penetration level, neglecting the interaction between new devices and micro-grids, as well as revealing little generation mechanisms about the PCC harmonic of renewable energy. In $[9,10]$, the generation mechanisms of multi-inverter resonances are studied by establishing inverter parallel models, and a virtual impedance method was proposed to suppress these resonances. On the other hand, the serial resonant frequencies between PV inverters and line impedances can also shift to the lower band because of the high line impedance in weak grid. The output harmonics of grid-tied PV inverters are generally concentrated in low-frequency bands, and it is probable to cause resonances at PCC [11]. In [12-14], the impedance matching analysis method of serial resonances between power converter groups and grid impedances is proposed, and a harmonic linearization model is studied. In [15-18], the companion harmonic circuit modeling is adopted to develop an electronic device and micro-grid combine model, which can analyze the adverse effects of harmonic distortion in weak grids. It also produces a very easy solution method.

For renewable energy generations, almost all dispatched loads and parallel reactive power compensating devices work in a frequently changing way [19]. The parameters of equivalent admittance/impedance of fundamental and harmonics of these equipment exist in uncertainty, which will significantly change the harmonic network admittance matrix of micro-grid [20]. Due to the rapid increase of photovoltaic systems in micro-grids, the problem of power quality associated with the intermittent nature of these systems had become more and more serious, and many efforts have been made already [21,22]. Most of the strategies about harmonic suppression in micro-grid focus on the power grid models containing one PV inverter, hence it is necessary to establish a model associated with a multi-inverter-based micro-grid [23,24]. In [25-29], a composite method to study the impact of harmonic sources on the distribution system is proposed. This approach combines a bottom-up stochastic modeling of the local loads with harmonic waveform data and power-flows all based on a scenario analysis. Based on the analysis of the measurement data, a prediction of the harmonic current level in a residential area can be performed by the method on the current situation. The purpose of this research is to study the harmonic generation mechanism and suppression method by establishing a combined model of micro-grid. In [30,31], it is mentioned that the phase-locked loop (PLL) is the most important grid synchronization technique in grid-connected power converter applications. However, its phase-tracking performance is affected seriously by the unbalances and distortions of micro-grid voltage. It is important for a grid-tied inverter, even when the grid is subject to harmonics, to maintain the harmonic contents of inverter output currents below the specified limit. Therefore, some research is focused on the inverter PLL performance to analyze the PV PCC harmonic generation mechanism in a micro-grid [32,33].

The studies above reveal a fact that the analysis of harmonic generation mechanisms are the key issues of harmonic mitigation for the power systems containing distributed generations, such as photovoltaics and wind generations. All the methodologies above of micro-grid harmonic research include theoretical analysis, modeling, simulation and experimental research. The study results obtained by these methodologies are not completely consistent with the actual results in field, such as PV PCC harmonics in micro-grid. Therefore, it is necessary to study the power quality problems in PV plants based on effective field testing and data measurement. In this paper, a field test and analysis method of a PV plant harmonics is presented, and a new generation mechanism of PV PCC harmonics is proposed.

\section{Analysis of PV PCC Harmonics}

To analyze the PCC harmonics of high-power PV plant with multiple grid-tied inverters, a micro-grid containing photovoltaic and hydroelectricity was addressed. This micro-grid is located in Batang Town, Yushu Prefecture, Qinghai Province, in western China, and the distance from large grid to the micro-grid is more than $400 \mathrm{~km}$. The capacity of hydroelectricity as the main power source of the micro-grid is $12.8 \mathrm{MW}$. The load peak of this micro-grid is $12 \mathrm{MW}$. Under the influence of the flood season and the dry season, hydroelectricity cannot meet the needs of power in winter. The power supply gap is large, especially during the peak hours in the evening. Therefore, the construction of a PV/energy-storage generation system was implemented to improve the power supply of the 
micro-grid. However, significant harmonics appear frequently at PCC of the PV plant when PV inverters are working. The micro-grid and PV plant are depicted in Figure 1.

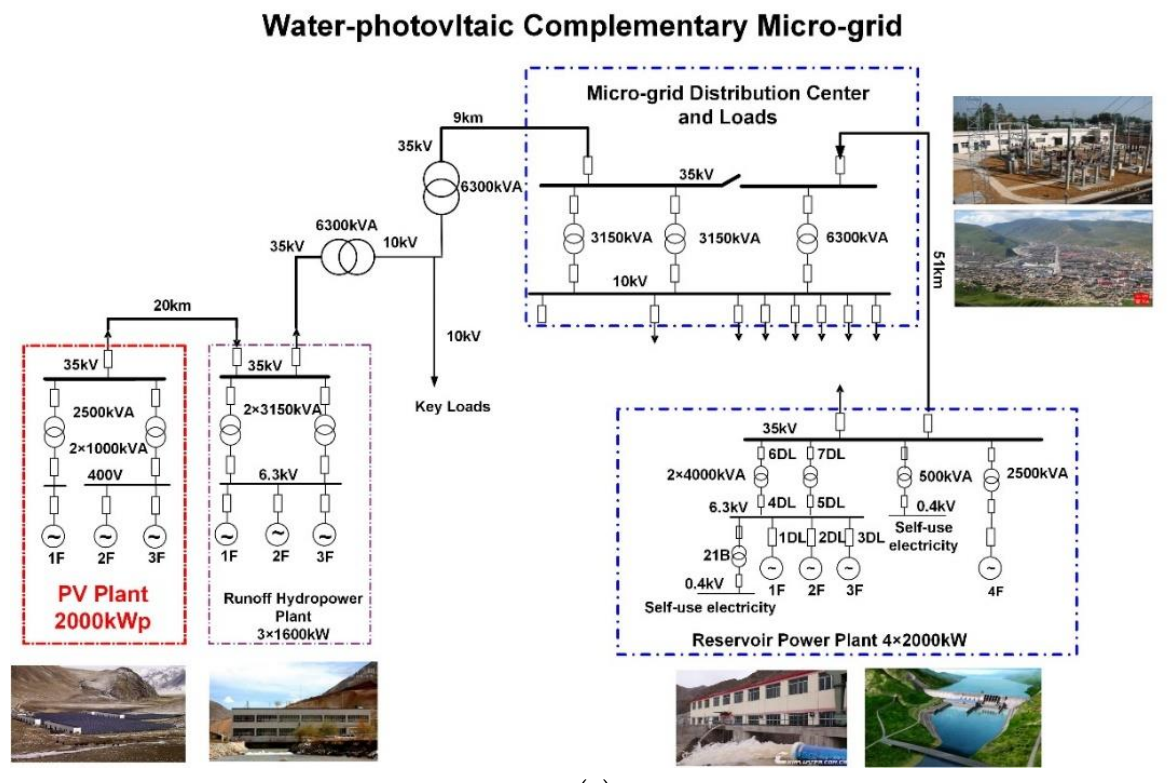

(a)

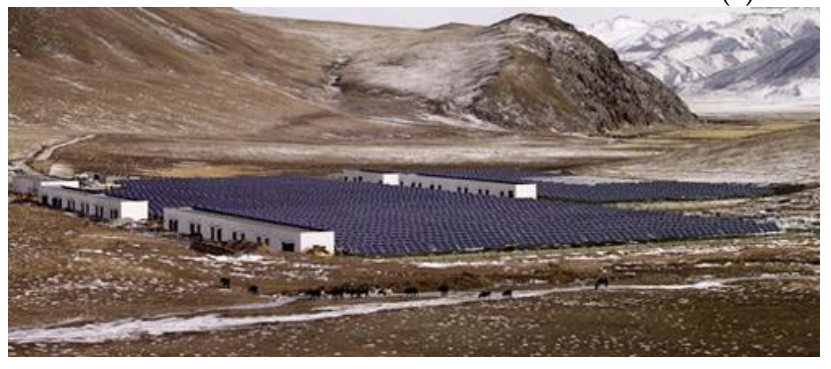

(b)

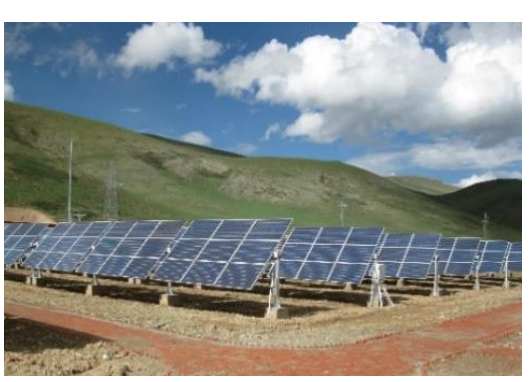

(c)

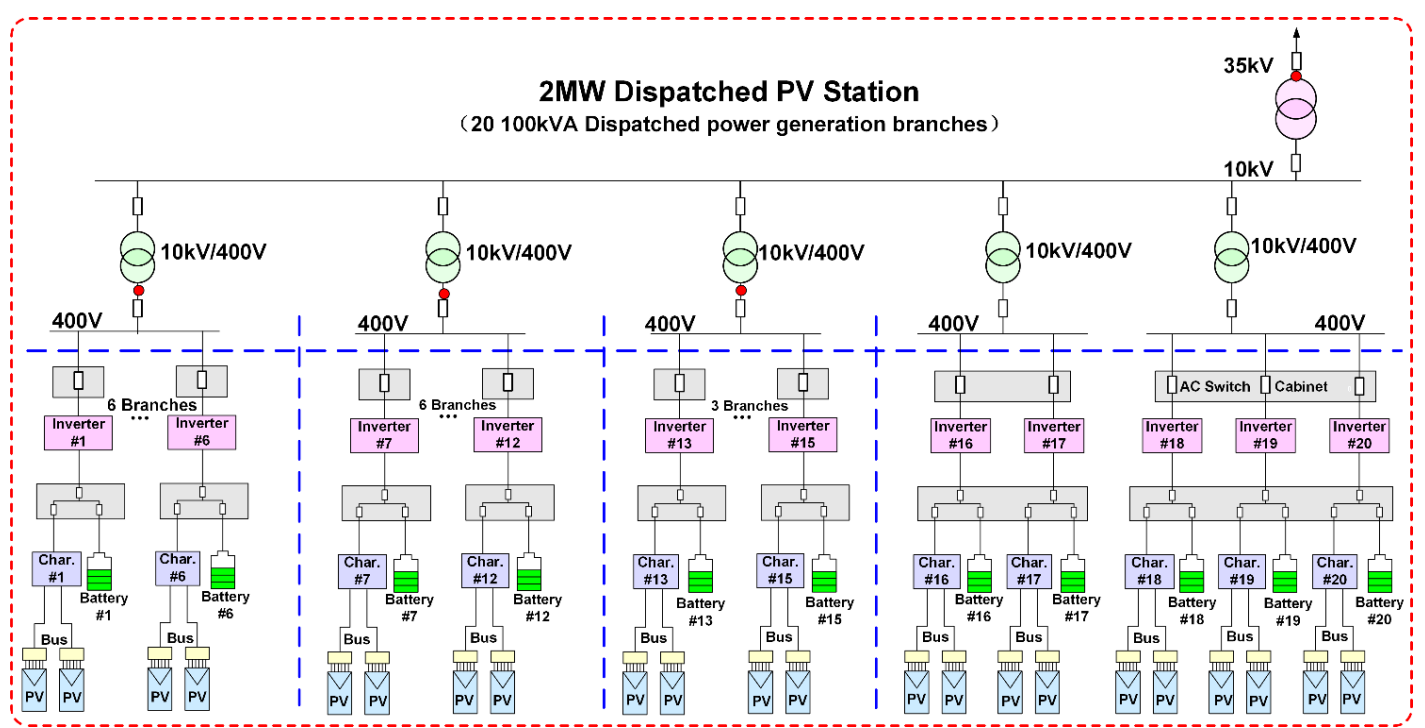

(d)

Figure 1. Photovoltaic (PV) plant of an isolated micro-grid: (a) the topology of Yushu water-photovoltaic micro-grid; (b) the aerial view of the PV plant in micro-grid; (c) the details of PV plant; and (d) topology of the PV plant. 
As illustrated in Figure 1, the capacity of the PV plant was 2 MWp, and the rated power of each inverter was $100 \mathrm{~kW}$. The topology of these inverters was a standard current-source converter (CSC) and the output filter consisted of an inductor and a capacitor. The capacitance and conductance of inverter filter were $47 \times 10^{-6} \mathrm{~F}$ and $0.25 \mathrm{mH}$, respectively. Each grid-tied transformer was connected by 3-6 PV inverters in parallel, and the transformers are connected to PV PCC of the microgrid. The ratio of these grid-tied transformers was $10 \mathrm{kV} / 400 \mathrm{~V}$, and the ratio of isolating transformer in PV inverters was $400 \mathrm{~V} / 215 \mathrm{~V}$. The proportional integral (PI) regulators in $d q$ reference frame were adopted by PV inverter controllers. The capacity of energy storage system was 15.60 MWh. As a result, the PV inverters were working with an ideal direct current (DC) supply and the harmonic analysis could focus on the PCC of PV plant. The grid-tied inverters and energy storage of PV plant are presented as Figure 2.

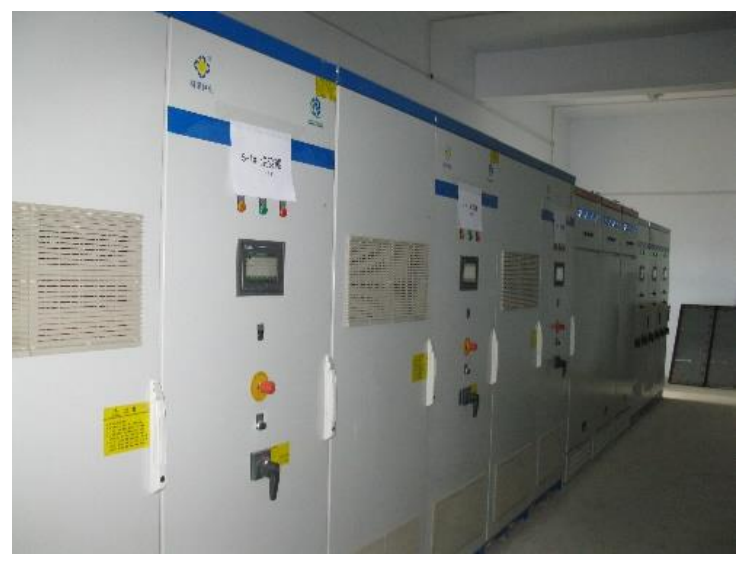

(a)

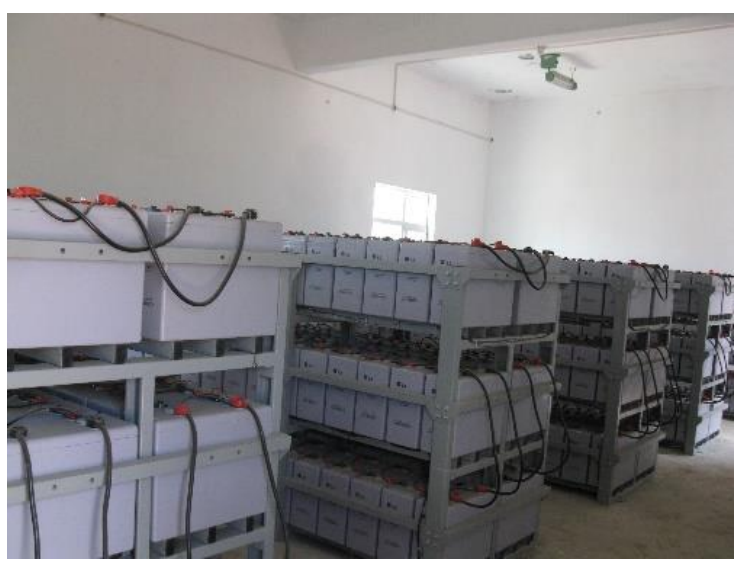

(b)

Figure 2. Equipment of PV plant: (a) PV inverters; and (b) energy storage systems.

PV inverters with different generation power were operated. The voltage and current waveforms of PCC with low output power of PV inverters are depicted as Figure 3.

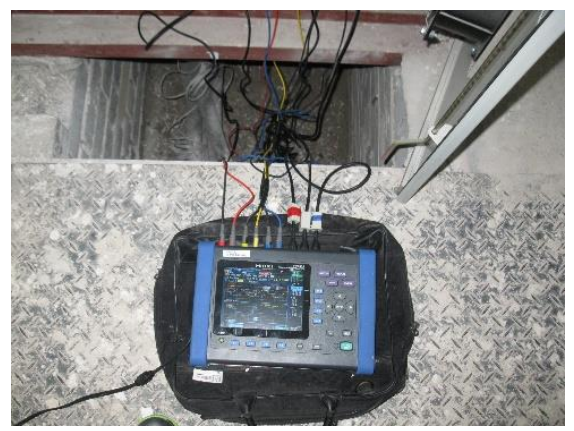

(a)

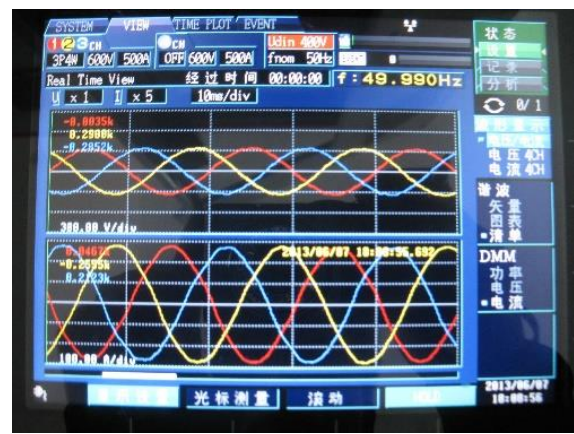

(b)

Figure 3. Waveforms of PV point of common coupling (PCC): (a) HIOKI-3196 power quality analyzer (HIOKI E.E. Corporation, 81 Koizumi Ueda, Nagano 386-1192, Japan); and (b) voltage and current waveforms at PCC of micro-grid.

As illustrated in Figure 3, the PCC waveforms were perfect. The harmonic waveforms, when the output power of PV plant was about $65 \%$ of rated value, are presented in Figure 4. 


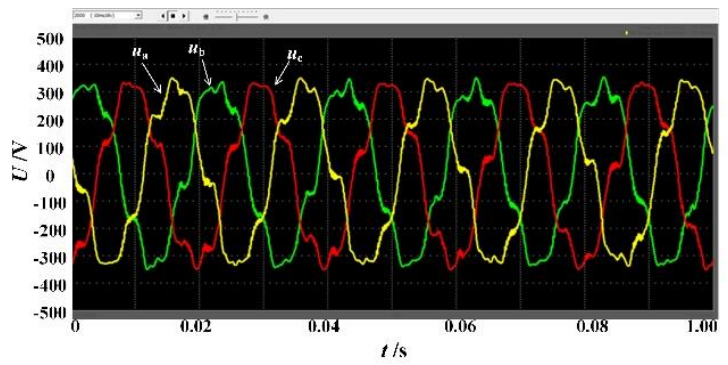

(a)

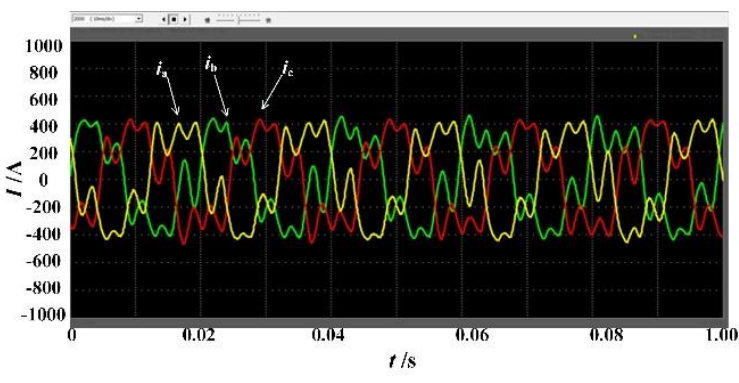

(b)

Figure 4. PCC waveforms of a PV plant: (a) the voltage waveforms at PV PCC; and (b) the current waveforms at PV PCC.

As illustrated in Figure 4, the waveforms of PCC voltage and current were recorded by data acquisition instrument YOKOGAWA DL850 ScopeCorder (Yokogawa Test \& Measurement Corporation, Musashino-shi, Tokyo 180-8750, Japan) and the sample frequency was $20 \mathrm{kHz}$. The main harmonic components were steady-state, and the harmonics were significant (total harmonic voltage distortion (THDU) of $15 \%$ and total harmonic current distortion (THDI) of $40 \%$ ). Total power factor was 0.95 and the power factor of fundamental signals was 0.99 . However, the voltage and current waveforms in Figure 4 were not symmetrical perfectly, and this phenomenon revealed the existence of inter-harmonics at PV PCC. There are spectral leakage and fence effects when any inter-harmonics are analyzed using discrete Fourier transform (DFT) or fast Fourier transform (FFT) algorithms. Therefore, the waveform measurement data in the PV plant of the micro-grid were analyzed using windowed interpolation Fourier transform (IpFFT) method.

IpFFT is an improved FFT algorithm with high frequency resolution and accurate analysis of signal phases and amplitudes [34,35]. The effects of spectral leakage and fence of DFT algorithm can be mitigated by IpFFT methods. Windowed interpolation Fourier transform algorithm based on Hamming window was employed in this study. The Hamming data window is as follows:

$$
w(n)=0.54-0.46 \cdot \cos \left(\frac{2 \pi n}{N-1}\right),(0 \leq n \leq N-1)
$$

The window is adopted to the signal data in time domain. DFT or FFT algorithm is employed to the windowed signals to obtain the signal spectra. More accurate amplitudes, frequencies and phases of signal spectra can be calculated by the IpFFT interpolation formula. The interpolation formula of Hamming IpFFT algorithm in frequency domain is presented as:

$$
\left\{\begin{array}{l}
\gamma=\frac{|X(l+1)|-|X(l)|}{|X(l+1)|+|X(l)|} \\
\delta=1.21874943 \gamma+0.13349531 \gamma^{3}+0.05301420 \gamma^{5}+0.03656014 \gamma^{7} \\
A_{l}=(|X(l)|+|X(l+1)|) \times\left(2.26557103+1.22719978 \delta^{2}\right. \\
\left.+0.37607775 \delta^{4}+0.09767389 \delta^{6}\right) \\
f_{l}=l+\delta+0.5 \\
\varphi_{l}=\angle X(l)+\delta \pi
\end{array}\right.
$$

where $X(l)$ and $X(l+1)$ are the highest and second highest spectral lines of one spectral peak of windowed signal spectrum, respectively; $\gamma$ is the interpolation factor; $\delta$ is the frequency deviation; and $A_{l}, f_{l}$ and $\varphi_{l}$ are the estimations of the amplitude, frequency and phase of a harmonic, and their units are $\mathrm{V}, \mathrm{Hz}$ and $\left({ }^{\circ}\right)$, respectively. 
The harmonic analysis results of phase A voltage and current of PV PCC signals by IpFFT algorithm are shown in Figure 5.

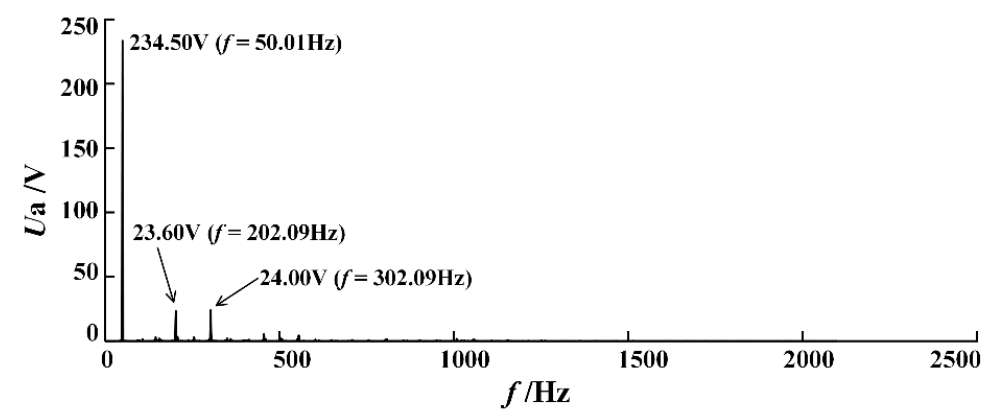

(a)

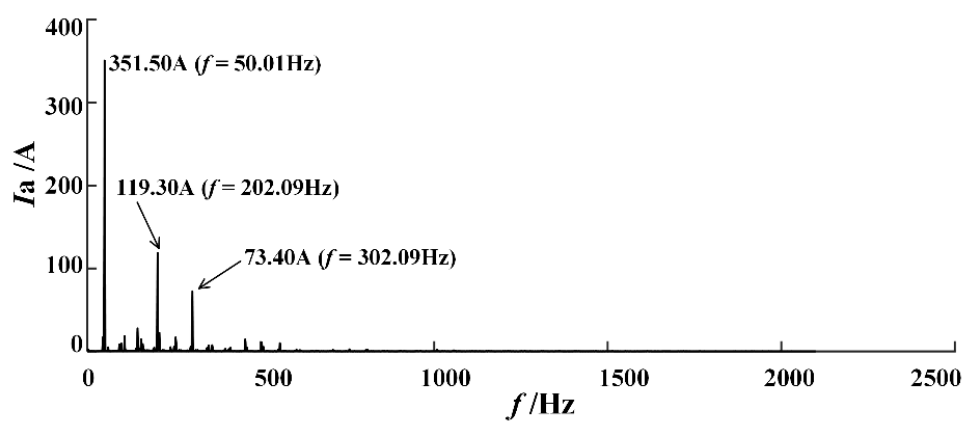

(b)

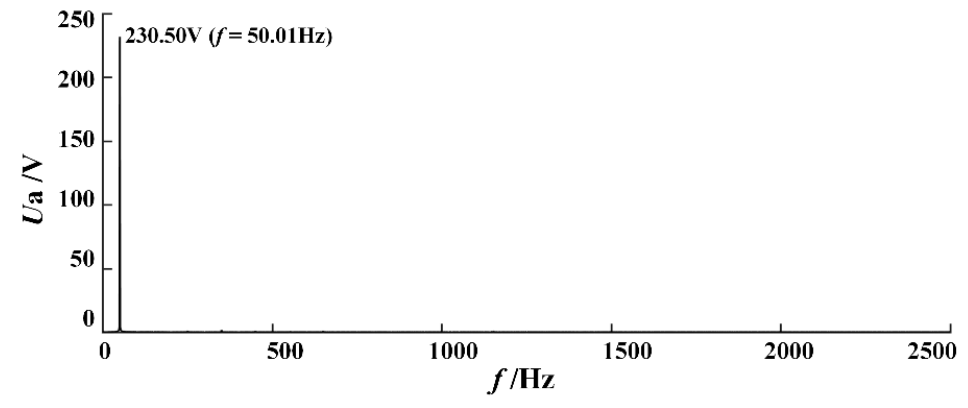

(c)

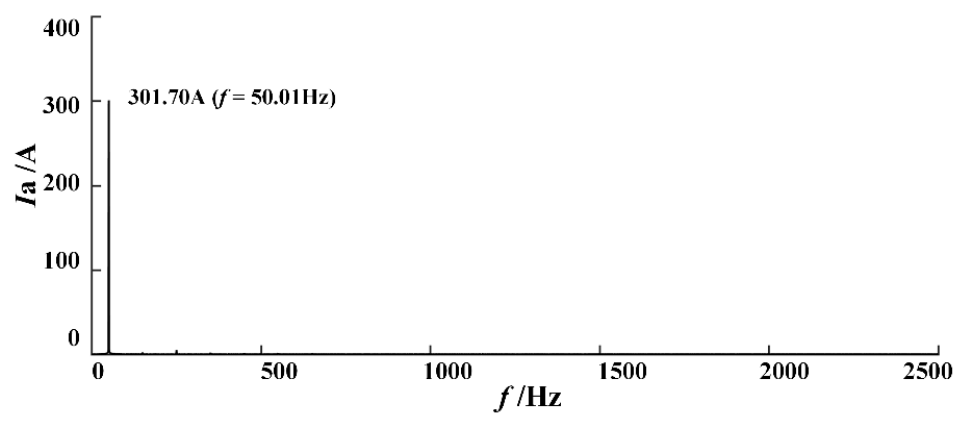

(d)

Figure 5. Spectra of phase A voltage and current at PV PCC: (a) spectra of phase A voltage while PCC harmonics occur; (b) spectra of phase A current while PCC harmonics occur; (c) spectra of phase A voltage while PCC harmonics disappear; and (d) spectra of phase A current while PCC harmonics disappear. 
As illustrated in Figure $5 c, d$, the spectra of PCC voltage and current waveforms recorded by DL850 ScopeCorder did not contain any significant background harmonics although the PV inverters were still working. When the production in the PV plant increased, as shown in Figure 5a,b, PCC harmonics occurred; the frequencies of the two significant harmonic components are $202.90 \mathrm{~Hz}$ and $302.90 \mathrm{~Hz}$. These components are inter-harmonics with frequencies near 4th and 6th harmonic frequencies. The frequencies of the two inter-harmonics are denoted as $f_{4}$ and $f_{6}$, respectively, and the fundamental frequency is denoted as $f_{1}$. The difference (denoted as $f_{6}-f_{4}-2 f_{1}$ ) of these harmonic frequencies and double fundamental frequencies during $40 \mathrm{~s}$ is presented in Figure 6.

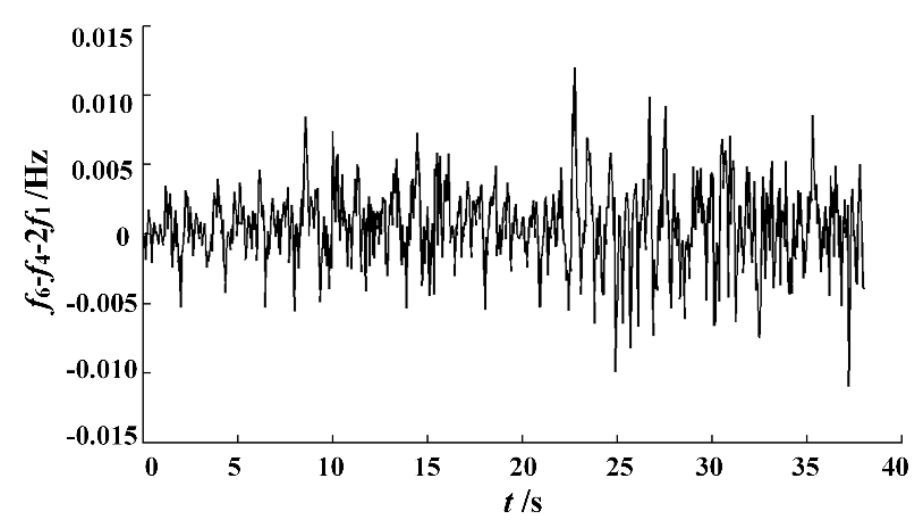

Figure 6. Frequency difference of harmonics at PV PCC.

The curve illustrated in Figure 6 reveals that the algebraic difference of the three frequencies is within the range of $(-0.01 \mathrm{~Hz}, 0.01 \mathrm{~Hz})$, and evenly distributed. It is considered that the frequency difference between the two inter-harmonics is twice the fundamental frequency $\left(2 f_{1}\right)$. The same frequency difference relationship exists between the two inter-harmonic components in the B-phase and C-phase signals. Such frequency difference relationship was satisfied as long as the PV PCC harmonics occurred. The waveforms recorded at other times led to the same results of the PCC harmonics in the PV plant. In addition, there is a special relationship between the phase sequences of PCC harmonics.

The phase sequences of the fundamental and inter-harmonics were calculated for $40 \mathrm{~s}$, as presented in Figure 7.
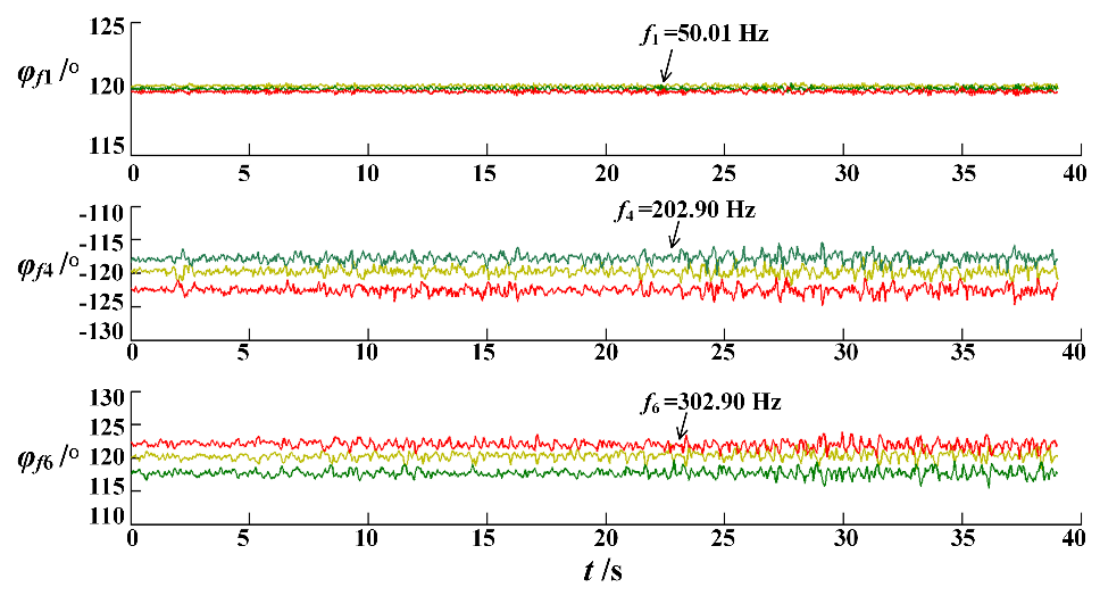

(a)

Figure 7. Cont. 


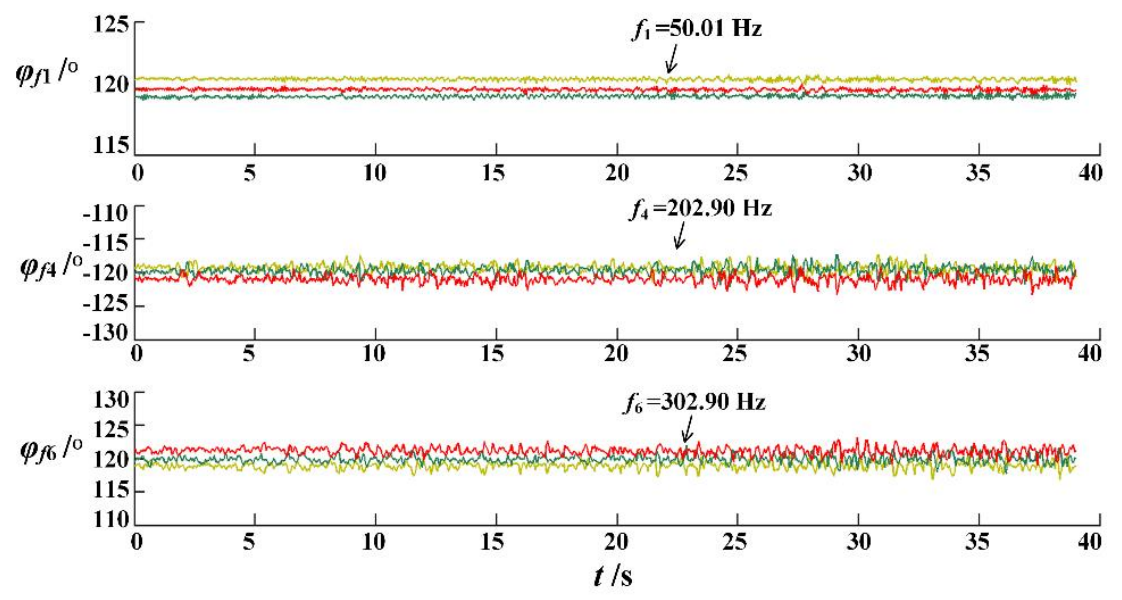

(b)

Figure 7. Phase sequences of voltage and current signals at PV PCC: (a) phase sequences of voltage signals at PV PCC; and (b) phase sequences of current signals at PV PCC.

The phase sequences of the fundamental and two inter-harmonics are denoted as $\varphi_{f_{1}}, \varphi_{f_{4}}$ and $\varphi_{f_{6}}$, where the yellow curves are phase A vs. phase B, the green curves are phase B vs. phase $C$, and the red curves are phase $C$ vs. phase $A$. The curves illustrated in Figure 7 indicate that the phase sequences of the inter-harmonics $\left(\varphi_{f_{4}}\right.$ and $\left.\varphi_{f_{6}}\right)$ are symmetric, such as the same phase difference and opposite phase sequence. Further analysis shows that the amplitudes of the two inter-harmonic voltages are very close, and all the voltage root mean square (RMS) are about $24.00 \mathrm{~V}$. The correlation of frequency, phase sequence and amplitude show that the inter-harmonics at PCC are not independent from each other and come from the same source. Therefore, it is inspiring to analyze the harmonics in the output circuits of PV grid-tied inverters.

\section{Harmonics of Inverter Outputs}

Single-phase output equivalent circuit of grid-tied inverters can be performed as Figure 8 when the three-phase output filter is symmetrical. The parameters of output circuits of PV inverters can be found in Table 1.

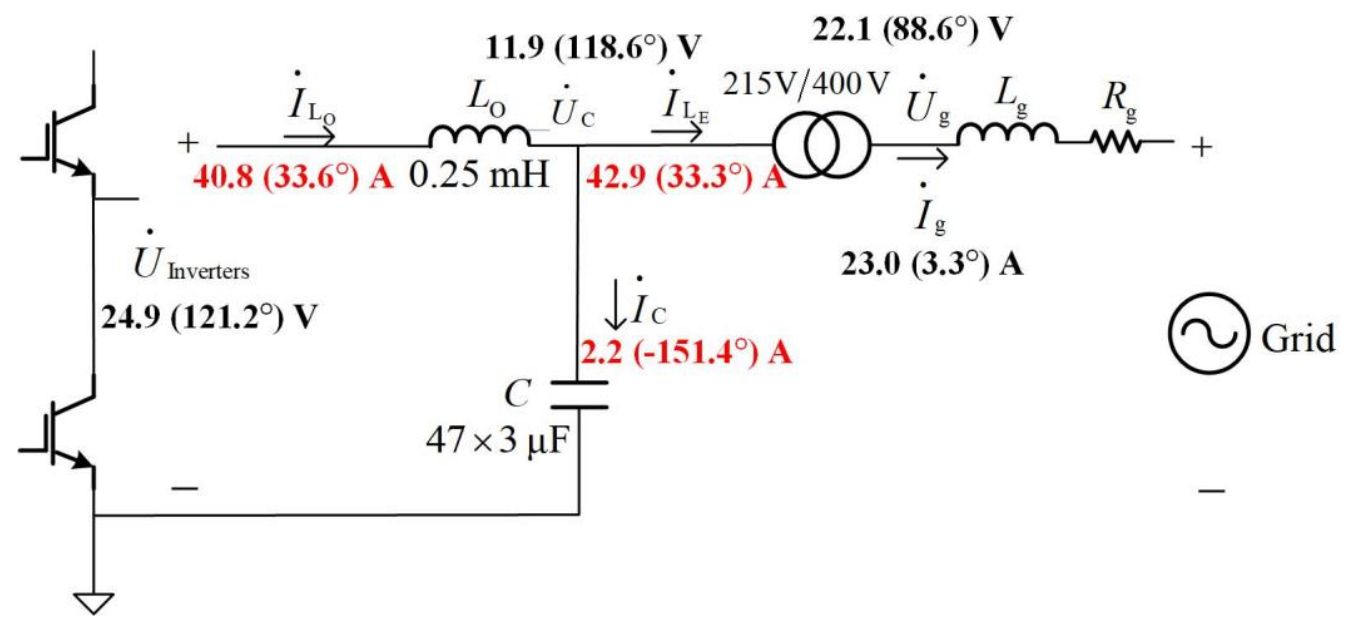

Figure 8. Distribution of $202.90 \mathrm{~Hz}$ inter-harmonic in the output filter. 
Table 1. Parameters of photovoltaic (PV) Inverter Filter Circuits. RMS: root mean square

\begin{tabular}{cc}
\hline Parameter Symbols & Values \\
\hline$L_{\mathrm{O}}$ & $0.25 \mathrm{mH}$ \\
$C$ & $47 \mathrm{uF}$ \\
$L_{\mathrm{g}}$ & $0.15 \mathrm{mH}$ (Calculated) \\
$R_{\mathrm{g}}$ & $0.15 \mathrm{Ohm}$ (Calculated) \\
$V_{\text {grid }}$ & $380 \mathrm{~V}$ (RMS) \\
$V_{\mathrm{DC}}$ & $400 \mathrm{~V}$ \\
\hline
\end{tabular}

$L_{\mathrm{O}}$ and $C$ are filtering inductor and capacitor, respectively; $L_{\mathrm{g}}$ and $R_{\mathrm{g}}$ are line impedances of the micro-grid, and the ratio of isolating transformer in the PV inverters is $400 / 215$. When the line resistor $R_{\mathrm{g}}$ can be ignored, the output impedance of PV inverter can be depicted as

$$
Z=j \omega \frac{L_{\mathrm{O}}+L_{\mathrm{E}}-\omega^{2} L_{\mathrm{O}} L_{\mathrm{E}} C}{1-\omega^{2} L_{\mathrm{E}} C}
$$

where $L_{\mathrm{E}}$ is the equivalent inductance of the isolating transformer in the PV inverters. The $L C L$ resonance frequencies of output equivalent impedance $Z$ are related to inductors $L_{O}$ and $L_{\mathrm{E}}$ and capacitor $C$.

Based on Kirchhoff's current law and the reference directions of branch currents of PV inverter output filter, the current equation below can be satisfied:

$$
-\dot{I_{\mathrm{L}}}+\dot{I_{\mathrm{L}_{\mathrm{E}}}}+\dot{I_{\mathrm{C}}}=0
$$

where $I_{\mathrm{L}_{\mathrm{O}}}$ is the RMS of inverter output inter-harmonic current, $I_{\mathrm{C}}$ is the RMS of capacitor branch current of inverter output filters, and $I_{\mathrm{LE}}$ is the RMS of the injected inter-harmonic current into micro-grid. When LCL resonances take place, the RMS of the currents above satisfy the following equation:

$$
I_{\mathrm{C}}=I_{\mathrm{L}_{\mathrm{O}}}+I_{\mathrm{L}_{\mathrm{E}}}
$$

The current vectors of LCL resonance are depicted in Figure 9.

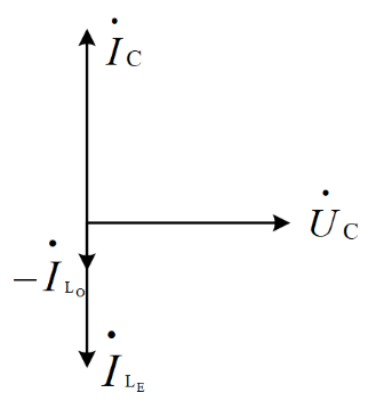

Figure 9. Current vectors of inductor branches and capacitor branch as LCL resonance occurring.

In Figure 8, considering the $202.90 \mathrm{~Hz}$ inter-harmonic, the red data are branch currents and the data in parentheses are the real-time phases of inter-harmonic currents. The inter-harmonic RMS current $I_{C}$ of $202.90 \mathrm{~Hz}$ in capacitor branch was $2.20 \mathrm{~A}$, which was less 1/15 of the RMS of inter-harmonic current $I_{\mathrm{LO}}$ or $I_{\mathrm{LE}}$ with the same frequency. $U_{\text {Inverters }}$ was the inverter inter-harmonic voltage at insulated gate bipolar transistor (IGBT)-bridge output of $202.90 \mathrm{~Hz}$, which was the significant one of $202.90 \mathrm{~Hz}$ in the PV inverter output circuit. Other frequency inter-harmonics at the PV PCC presented the same characteristics in the inverter output circuits. The analysis results are shown in Table 2. 
Table 2. Currents and Voltages of the Inter-harmonics.

\begin{tabular}{cccc}
\hline$f(\mathbf{H z})$ & $\mathbf{1 4 4 . 6 0}$ & $\mathbf{2 0 2 . 9 0}$ & $\mathbf{3 0 2 . 9 0}$ \\
\hline$I_{\mathrm{L}_{\mathrm{O}}}(\mathrm{A})$ & $5.47\left(-70.8^{\circ}\right)$ & $40.75\left(3.6^{\circ}\right)$ & $25.99\left(-23.6^{\circ}\right)$ \\
$I_{\mathrm{L}_{\mathrm{E}}}(\mathrm{A})$ & $5.58\left(-70.9^{\circ}\right)$ & $42.88\left(3.3^{\circ}\right)$ & $29.56\left(-23.8^{\circ}\right)$ \\
$I_{\mathrm{C}}(\mathrm{A})$ & $0.11\left(103.8^{\circ}\right)$ & $2.14\left(178.6^{\circ}\right)$ & $3.57\left(154.4^{\circ}\right)$ \\
$U_{\mathrm{C}}(\mathrm{V})$ & $0.85\left(13.8^{\circ}\right)$ & $11.90\left(88.6^{\circ}\right)$ & $13.32\left(64.4^{\circ}\right)$ \\
$U_{\text {Inverters }}(\mathrm{V})$ & $2.09\left(17.0^{\circ}\right)$ & $24.86\left(91.2^{\circ}\right)$ & $25.68\left(65.4^{\circ}\right)$ \\
\hline
\end{tabular}

All branch harmonic currents and node voltages presented in Table 2 had the following characteristics: the capacitor inter-harmonic currents $\left(I_{C}\right)$ are very small and much smaller than inductor branch harmonic currents $\left(I_{\mathrm{L}_{\mathrm{O}}}\right.$ and $\left.I_{\mathrm{L}_{\mathrm{E}}}\right)$; and harmonic voltages at inverter bridge $\left(U_{\text {Inverters }}\right)$ are twice of the harmonic voltages at filter capacitor $\left(U_{\mathrm{C}}\right)$.

As illustrated in Equation (5), the LCL resonance of PV inverter filter usually generates a significant inter-harmonic current in capacitor branch, and the voltage RMS of filtering capacitor is the biggest one of all the node inter-harmonic voltages in the inverter output circuits. However, the results of field measurement and data analysis were very different to the LCL resonance: the inter-harmonic voltages and currents in filtering capacitor branches were not significant anymore. The harmonic currents $\left(I_{C}\right)$ of the capacitor branches are very small, and the installation of the damping resistors in the capacitor branches did not suppress the harmonics. Therefore, it can be concluded that the inter-harmonics at PV PCC are not generated by LCL resonances of inverter output filters, and the investigations of harmonics at PV PCC in the PV plant should be associated with the inverter control methods, PV plant topology and micro-grid impedances.

When the line impedances are significant (in weak grid), parallel resonances may occur among multiple PV inverters tied in the same PV PCC, and series resonances may occur between the inverter group and line impedances. The latest studies indicate that the parallel or series resonant frequencies are related to the number of inverters operating in parallel: the more inverters there are, the lower frequencies the resonance have [8-11]. There is a set of measurement data obtained by field test that contained the PCC harmonic waveforms as one PV inverter was online and then offline. Six inverters in the PV plant were connected to one grid-tied transformer in parallel. The waveforms of voltages and currents at PV PCC of changing the number of PV inverters in parallel were specifically studied and the analysis results are presented in Figure 10.

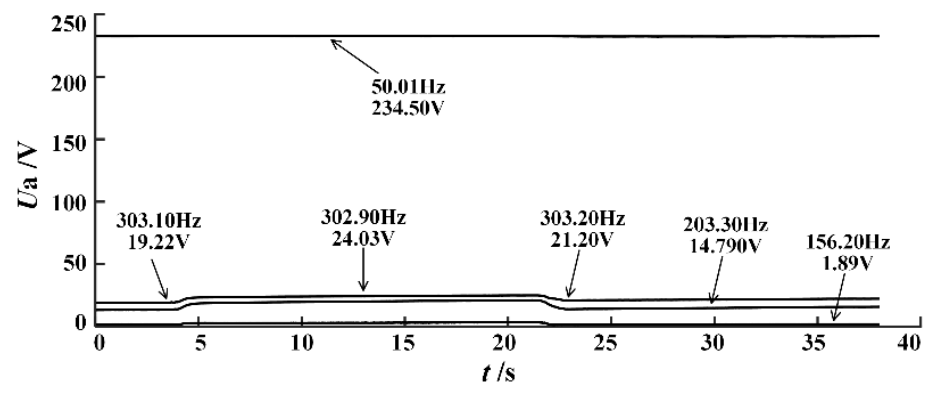

(a)

Figure 10. Cont. 


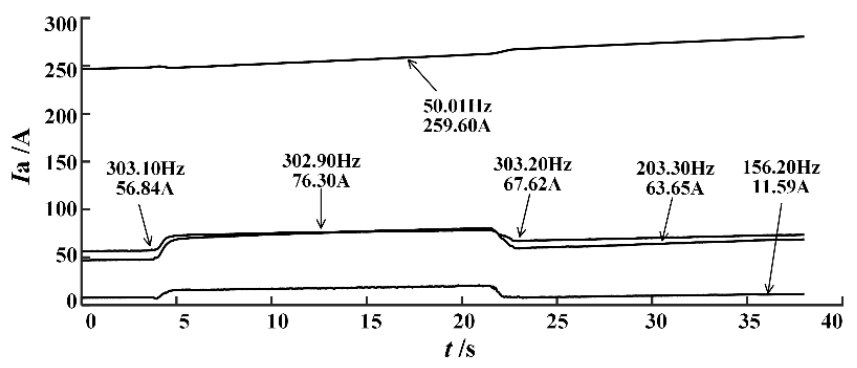

(b)

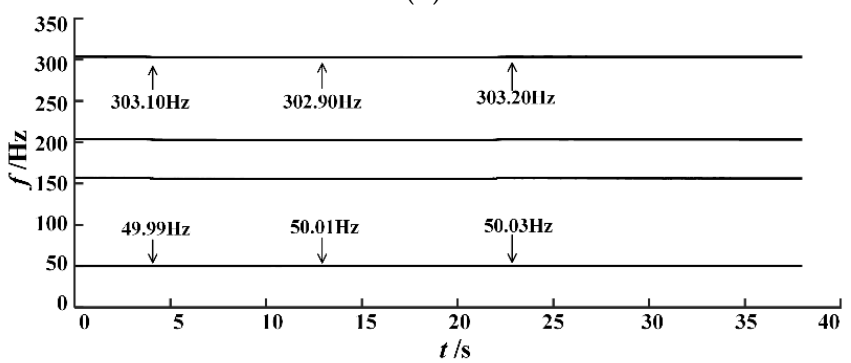

(c)

Figure 10. The harmonic varieties vs. the quantity of PV inverters in parallel at PCC: (a) voltage RMS of PCC harmonics vs. time; (b) current RMS of PCC harmonics vs. time; and (c) frequencies of PCC harmonics vs. time. RMS: root mean square.

As illustrated in Figure 10, the harmonic voltages and currents increased significantly at the time of $5 \mathrm{~s}$, which indicates that one inverter was start-up; all harmonic voltages and currents were stepped down at the time of $22 \mathrm{~s}$, indicating that one inverter was shutdown. During the start-up and shutdown of the inverter, there was almost no change in the inter-harmonic frequencies at PV PCC. In this case, the effect of changing the number of PV inverters in parallel was that the harmonic voltage and current amplitudes changed but the frequencies did not. It can be considered that the harmonic frequencies at PCC in the PV plant were not related with the number of grid-tied inverters, and the harmonics were not generated by the series/parallel resonances of multi-inverters.

\section{Harmonic Sources and Simulations}

As illustrated in Figure $5 c, d$, when the PV inverters were running but no "resonances" existed, the spectra of PV PCC waveforms contained fundamental voltage and current components only. Figure $5 c, d$ reveals no background harmonics in the micro-grid. To determine the position of harmonic source, the $d q$ conversion was implemented to the three-phase voltage at PCC and obtained sinusoidal ripples on the $d q$ axis of the inverter output (DC component removed). The results are depicted in Figure 11.

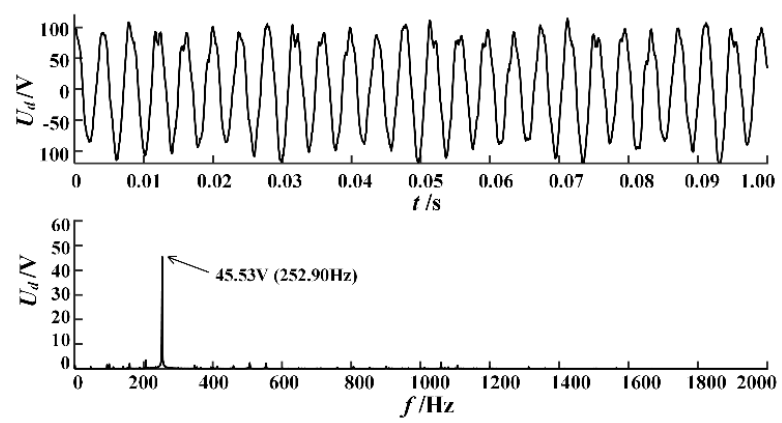

(a)

Figure 11. Cont. 

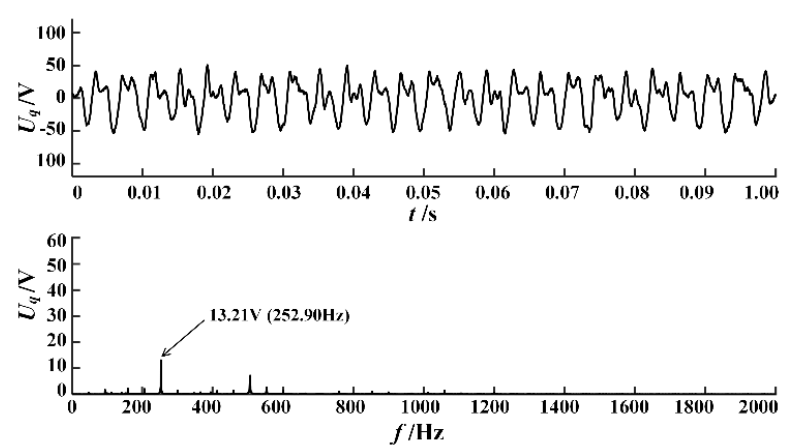

(b)

Figure 11. Harmonic voltage at $d$-axis and $q$-axis: (a) harmonic voltages and spectra at $d$-axis; and (b) harmonic voltages and spectra at $q$-axis.

As illustrated in Figure 11, there were $252.90 \mathrm{~Hz}$ ripples with high amplitudes on $d$-axis and $q$-axis of PV inverters. The inter-harmonics $(202.90 \mathrm{~Hz}$ and $302.90 \mathrm{~Hz})$ with significant amplitudes at PCC were generated by this sinusoidal alternating component. This sinusoidal alternating component was generated by nonlinear self-oscillation of PV inverters and micro-grid systems.

To verify the opinions of nonlinear self-oscillation to generate harmonics at PV PCC, a Simulink (Ver. R2016a, Mathworks, Natick, MA. 01760-2098, USA, 2016) model of "PV inverter and micro-grid" is implemented based on the actual parameters of PV inverters and line impedances of the micro-grid in field, as shown in Figure 12. The PV inverter works in current source mode; the inputs of PV inverter are connected to an energy storage system with constant DC voltage as the PV plant; PLL is based on PCC voltages to produce the real-time phase information; PI control algorithm is adopted by inverter controller in $d q$ domain; and a special self-oscillation source is used to generate steady-state oscillation signals to equivalent to all nonlinear factors of the "grid-tied inverter and weak grid" system.

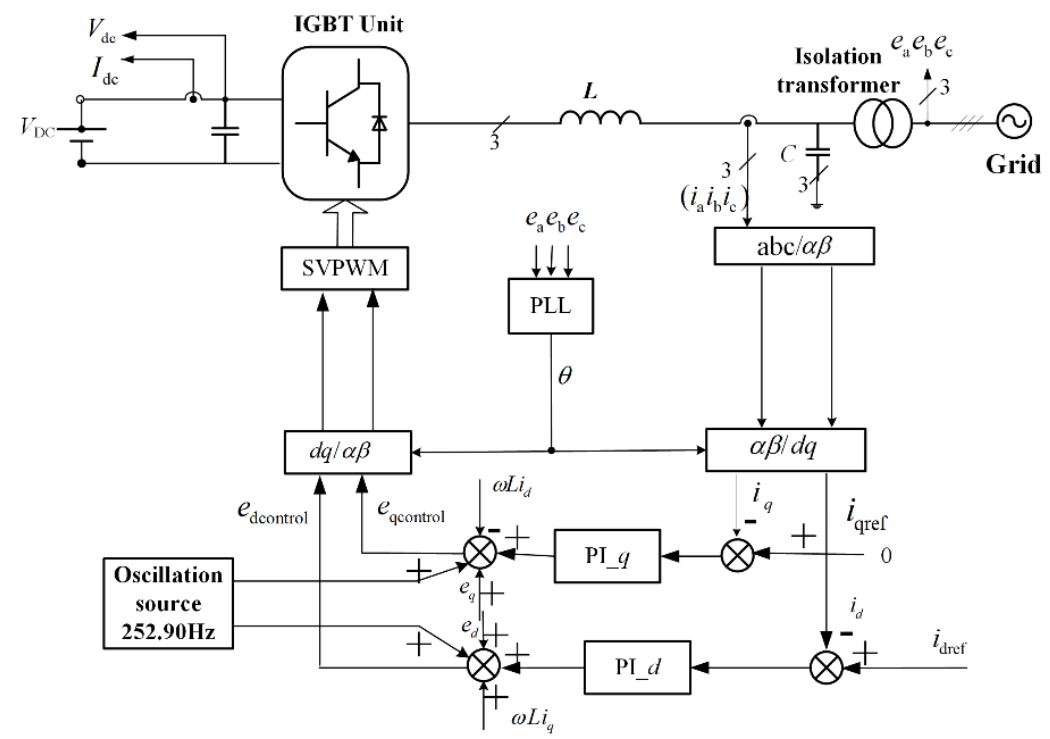

Figure 12. Simulation of nonlinear self-oscillations of PV grid-tied inverters.

$V_{\mathrm{DC}}$ is an ideal DC source with $400 \mathrm{~V}$ voltage; the phase voltage of micro-grid is $220 \mathrm{~V} \mathrm{AC}$; and the $\mathrm{P}$ and I parameters of controller are 0.03 and 0.01 , respectively. The equivalent inductance and resistance of line impedances are $0.15 \mathrm{mH}$ and $0.15 \Omega$, respectively, which were calculated according to the harmonic voltages and currents measured at PV PCC in field. The output filter and isolation 
transformer have the same parameters, as shown in Figure 8. The "oscillation source" in Figure 12 can generate a sinusoidal signal with frequency of $252.90 \mathrm{~Hz}$ which is employed to the $d$-axis and $q$-axis of the inverter, and the inter-harmonics with frequencies of $202.90 \mathrm{~Hz}$ and $302.90 \mathrm{~Hz}$ appear at the PV PCC. The waveforms and spectra of these inter-harmonics are presented in Figure 13.

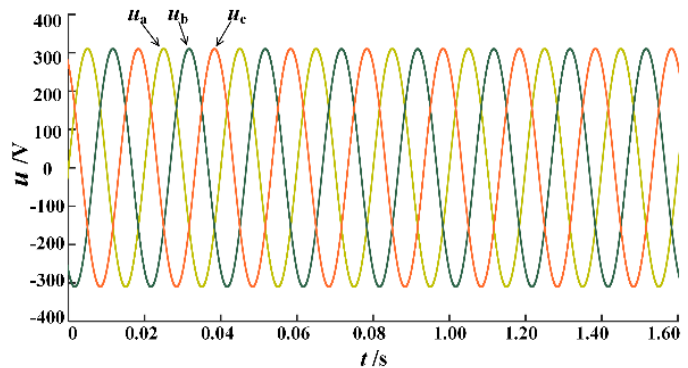

(a)

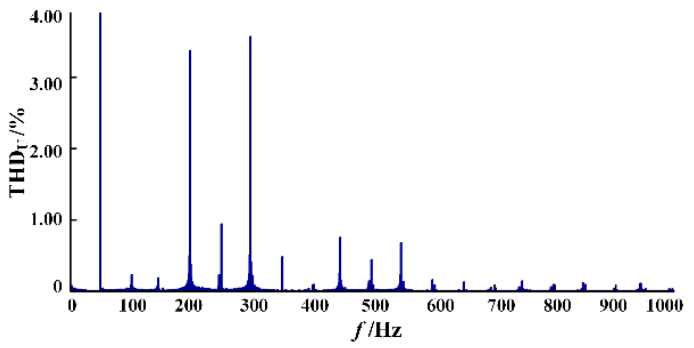

(c)

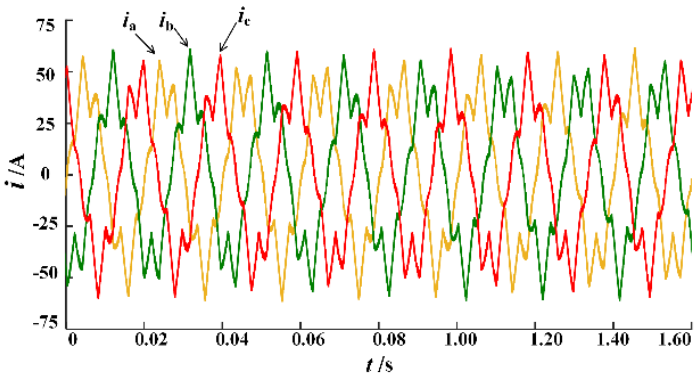

(b)

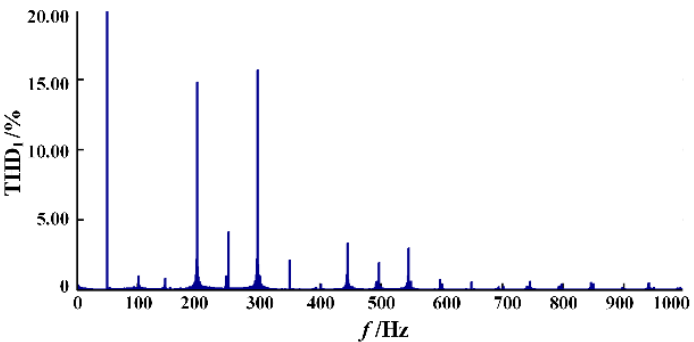

(d)

Figure 13. Waveforms and spectra of the harmonics at PV PCC of simulation: (a) voltages at PV PCC; (b) currents at PV PCC; (c) spectra of the voltages $\left(\mathrm{THD}_{\mathrm{U}}=5.60 \%\right)$; and (d) spectra of the currents $\left(\mathrm{THD}_{\mathrm{I}}=24.56 \%\right)$.

As illustrated in Figure 13, significant harmonics appear at PCC and the current THD exceeds $24.50 \%$. The simulation shows that the pulsation signals in PV inverters are the key source of the steady inter-harmonics of PV inverter outputs. The discussion below presents that the pulsation signal is generated by nonlinear self-oscillation of the "inverter-weak grid" system.

\section{Discussion}

According to the study above, the main characteristics of the harmonics at PCC of the PV plant are summarized as follows:

(1) The harmonics at PV PCC are steady-state inter-harmonics.

(2) The spectra of PV PCC harmonics are isolated spectral lines.

(3) The transition times of the harmonic appearance and fading are all very short.

(4) The frequencies and amplitudes of the harmonics are insensitive to external conditions.

It is proposed that the inter-harmonics at PCC of PV plant in field were generated by nonlinear self-oscillation of the "inverter-weak grid" system. A stable self-oscillation occurs inside the grid-tied PV inverters, and the harmonic frequencies did not depend on the linear characteristics of the inverters and the micro-grid. The nonlinear properties leading to nonlinear self-oscillations of the "inverter-weak grid" system are related to the integral saturation of inverter controller, PLL, hysteresis loop of grid-tied transformers, and dead-zones of IGBT-bridge of PV inverters.

The nonlinear dynamics also explain that the self-oscillations of nonlinear systems mainly include two categories: (1) periodic/quasi-periodic/chaotic oscillation with larger amplitude; and (2) weakly damped oscillation near the equilibrium with small amplitude. The nonlinear self-oscillation studied in 
this project belongs to the first type. In fact, the "grid-tied inverter-weak grid" system has the necessary conditions for self-oscillation: the energy conversion and energy supplement loop correspond to the invert-units and the DC sources of PV inverters; the frequency selective network corresponds to the output impedances of PV inverters, filter circuit equivalent impedances, and the line impedances of micro-grid; and the amplitude stable mechanism involves all the nonlinear properties in PV inverter-grid system. Therefore, the nonlinear self-oscillation theory proposed here reveals the essential mechanism of the harmonic generation at PV PCC in a micro-grid.

As discussed in the Introduction, the conventional methodologies of micro-grid harmonic research all include theoretical analysis, modeling, simulation and experiments. The preset of these studies was that the micro-grid and grid-tied inverters were linear systems. If any nonlinear characteristics were encountered, they should be treated by linearization. Most publications have reported from theoretical point of view, but there is no field verification in a real PV plant. In this study, the field waveforms were captured in a high-power PV plant to figure out the nonlinear self-oscillation mechanism of the harmonic phenomena in micro-grid. In fact, almost all the power quality problems in micro-grid including PV PCC harmonics come from real projects, therefore, field testing, real-time measurements and detailed data analysis are necessary for harmonic analysis and harmonic mitigations. The nonlinear self-oscillation theories proposed here and the research methodologies based on field data are worth being discussed.

\section{Conclusions}

This paper has proposed the nonlinear self-oscillation concept to clarify the mechanism of the harmonic resonance in a real high-power PV plant. The findings indicate that the main components of the harmonic signals are steady-state inter-harmonics. These inter-harmonics have correlations in frequencies, amplitudes and phase sequences, and the different harmonics at PV PCC are generated by the same source inside PV inverters. Based on the similarities of PCC harmonics and periodic steady-state outputs of nonlinear systems, the nonlinear self-oscillation concept was established to reveal the mechanism of the harmonic resonance in a high-power PV plant. The simulations clarified and confirmed the nonlinear self-oscillation theory of harmonic generation mechanism of PV PCC harmonics in micro-grids. In addition, the windowed interpolation Fourier transform (IpFFT) algorithm was adopted to analyze the field data of PV plant accurately, and the results indicate that IpFFT algorithm is an effective tool for harmonic analysis. This study has expanded the understanding of the harmonic generation mechanism of grid-tied PV plants in micro-grids.

Author Contributions: Y.Z. (Yong Zhao) and Z.Y. conceived the main idea and performed the tests, data analysis and wrote the manuscript. Y.W. contributed to the test and simulation environment. Y.Z. (Ying Zhang) gave suggestions and data processing.

Funding: This research was funded by the National Key R\&D Program of China (the key technologies and demonstrative application for the integration and consumption of clustered distributed renewable energy generation) (2016YFB0900400).

Acknowledgments: Yuanqing Yao checked and revised the English grammar of the text.

Conflicts of Interest: The authors declare no conflict of interest.

\section{References}

1. Guo, X.; Yang, Y.; Zhu, T.Y. ESI: A novel three-phase inverter with leakage current attenuation for transformerless PV systems. IEEE Trans. Ind. Electron. 2018, 65, 2967-2974. [CrossRef]

2. Qiang, G. A novel CH5 inverter for single-phase transformerless photovoltaic system applications. IEEE Trans. Circuits Syst. 2017, 64, 1197-1201.

3. Guo, X.; Yang, Y.; Zhang, X. Advanced control of grid-connected current source converter under unbalanced grid voltage conditions. IEEE Trans. Ind. Electron. 2018, 65, 9225-9233. [CrossRef] 
4. Guo, X.; We, B.; Zhu, T.; Lu, Z.; Tan, L.; Sun, X.; Zhang, C. Leakage current suppression of three phase flying capacitor PV inverter with new carrier modulation and logic function. IEEE Trans. Power Electron. 2018, 33, 2127-2135. [CrossRef]

5. Jian, S. Impedance-based stability criterion for grid-connected inverters. IEEE Trans. Power Electron. 2011, 26, 3075-3078.

6. Kresimir, F.; Zvonimir, K.; Ljubomir, M. Expansion of the residential photovoltaic systems and its harmonic impact on the distribution grid. Renew. Energy 2012, 43, 140-148.

7. Liu, J.; Wang, Y.B. Low frequency ripple behavior of PWM switching DC-DC converters. Proc. CSEE 2004, 24, 174-178.

8. Jian, S.; Jorge, C. Input impedance modeling of line-frequency rectifiers by the method of impedance mapping. In Proceedings of the 2006 IEEE Workshops on Computers in Power Electronics, Troy, NY, USA, 16-19 July 2006; pp. 69-75.

9. Sun, J. Small-signal methods for ac distributed power systems-A review. IEEE Trans. Power Electron. 2009, 24, 2545-2554.

10. He, J.W.; Li, Y.W.; Bosnjak, D.; Harris, B. Investigation and active damping of multiple resonances in a parallel-inverter-based microgrid. IEEE Trans. Power Electron. 2013, 28, 234-246. [CrossRef]

11. Xu, J.; Xie, S.; Tang, T. Evaluations of current control in weak grid case for grid-connected LCL-filtered inverter. IET Power Electron. 2013, 6, 227-234. [CrossRef]

12. Anthoula, M.; Thomas, Z.; John, M.A. Harmonic distortion assessment for a single-phase grid-connected photovoltaic system. Renew. Energy 2011, 36, 360-368.

13. Sun, J.; Bing, Z.; Kamiar, J.K. Input impedance modeling of multipulse rectifiers by harmonic linearization. IEEE Trans. Power Electron. 2009, 24, 2812-2820.

14. Cespedes, M.; Sun, J. Impedance modeling and analysis of grid-connected voltage-source converters. IEEE Trans. Power Electron. 2014, 29, 1254-1261. [CrossRef]

15. Cespedes, M.; Sun, J. Adaptive control of grid-connected inverters based on online grid impedance measurements. IEEE Trans. Sustain. Energy 2014, 5, 516-523. [CrossRef]

16. Lin, T.; Chen, R.; Yu, G.; Bi, R.; Xu, X. Extended Gersgorin Theorem-Based Parameter Feasible Domain to Prevent Harmonic Resonance in Power Grid. Energies 2017, 10, 1612. [CrossRef]

17. Milanes-Montero, M.-I.; Barrero-Gonzalez, F.; Pando-Acedo, J.; Gonzalez-Romera, E.; Romero-Cadaval, E.; Moreno-Munoz, A. Active, Reactive and Harmonic Control for Distributed Energy Micro-Storage Systems in Smart Communities Homes. Energies 2017, 10, 448. [CrossRef]

18. Guo, X.; Jia, X. Hardware-based cascaded topology and modulation strategy with leakage current reduction for transformerless PV systems. IEEE Trans. Ind. Electron. 2016, 62, 7823-7832. [CrossRef]

19. Dong, H.; Yuan, S.; Han, Z.; Cai, Z.; Jia, G.; Ge, Y. A Comprehensive Strategy for Accurate Reactive Power Distribution, Stability Improvement, and Harmonic Suppression of Multi-Inverter-Based Micro-Grid. Energies 2018, 11, 745. [CrossRef]

20. Yu, K.-N.; Yau, H.-T.; Liao, C.-K. Development of a Fractional Order Chaos Synchronization Dynamic Error Detector for Maximum Power Point Tracking of Photovoltaic Power Systems. Appl. Sci. 2015, 5, 1117-1133. [CrossRef]

21. Jayaraman, M.; VT, S. Power Quality Improvement in a Cascaded Multilevel Inverter Interfaced Grid Connected System Using a Modified Inductive-Capacitive-Inductive Filter with Reduced Power Loss and Improved Harmonic Attenuation. Energies 2017, 10, 1834. [CrossRef]

22. Yan, X.; Zhang, X.; Zhang, B.; Ma, Y.; Wu, M. Research on Distributed PV Storage Virtual Synchronous Generator System and Its Static Frequency Characteristic Analysis. Appl. Sci. 2018, 8, 532. [CrossRef]

23. Shi, T.; Wu, L.; Yan, Y.; Xia, C. Harmonic Spectrum of Output Voltage for Space Vector Pulse Width Modulated Ultra Sparse Matrix Converter. Energies 2018, 11, 390.

24. Guo, X.; Xu, D.; Guerrero, J.M.; Wu, B. Space vector modulation for dc-link current ripple reduction in back-to-back current-source converters for microgrid applications. IEEE Trans. Ind. Electron. 2015, 62, 6008-6013. [CrossRef]

25. Guo, X.; Yang, Y.; He, R.; Wang, B.; Blaabjerg, F. Transformerless Z-source four-leg PV inverter with leakage current reduction. IEEE Trans. Power Electron. 2018. [CrossRef] 
26. Oliveira, T.E.C.; Carvalho, P.M.S.; Ribeiro, P.F.; Bonatto, B.D. PV Hosting Capacity Dependence on Harmonic Voltage Distortion in Low-Voltage Grids: Model Validation with Experimental Data. Energies 2018, 11, 465. [CrossRef]

27. Guo, X.; Zhang, X.; Guan, H.; Kerekes, T.; Blaabjerg, F. Three phase ZVR topology and modulation strategy for transformerless PV system. IEEE Trans. Power Electron. 2018. [CrossRef]

28. Brando, G.; Dannier, A.; Del Pizzo, A.; Spina, I. Control and Modulation Techniques for a Centralized PV Generation System Grid Connected via an Interleaved Inverter. Appl. Sci. 2016, 6, 261. [CrossRef]

29. Vergura, S.; Carpentieri, M. Phase Coherence Index, HHT and Wavelet Analysis to Extract Features from Active and Passive Distribution Networks. Appl. Sci. 2018, 8, 71. [CrossRef]

30. Qiang, G.; Wu, W.; Chen, Z. Multiple-complex coefficient-filter-based phase-locked loop and synchronization technique for three-phase grid interfaced converters in distributed utility networks. IEEE Trans. Ind. Electron. 2011, 58, 1194-1204.

31. Guo, X.; Liu, W.; Lu, Z. Flexible power regulation and current-limited control of grid-connected inverter under unbalanced grid voltage faults. IEEE Trans. Ind. Electron. 2017, 64, 7425-7432. [CrossRef]

32. Nguyen, T.H.; Kim, K.-H. Finite Control Set-Model Predictive Control with Modulation to Mitigate Harmonic Component in Output Current for a Grid-Connected Inverter under Distorted Grid Conditions. Energies 2017, 10, 907. [CrossRef]

33. Guo, X.; Yang, Y.; Wang, X. Optimal space vector modulation of current source converter for dc-link current ripple reduction. IEEE Trans. Ind. Electron. 2018. [CrossRef]

34. Thomas, G. Interpolation algorithms for discrete Fourier transforms of weighted signals. IEEE Trans. IM 1983, 32, 350-355.

35. Du`san, A. Weighted multipoint interpolated DFT to improve amplitude estimation of multifrequency signal. IEEE Trans. IM 2002, 51, 287-292.

(C) 2018 by the authors. Licensee MDPI, Basel, Switzerland. This article is an open access article distributed under the terms and conditions of the Creative Commons Attribution (CC BY) license (http://creativecommons.org/licenses/by/4.0/). 